\title{
Des doutes
}

\section{Hans Stalder}

Prof. Dr méd., membre de la rédaction

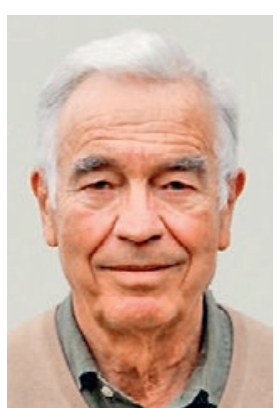

Il y a quelque chose de logique, et même de moral, dans le fait que ce soient surtout nous, les vieux, qui payons le plus lourd tribut à cet ogre sans frontières. Raison de plus pour lui échapper, dis-je.*

Je suis heureux! Je n'ai pas attrapé le coronavirus et j’ai reçu les deux doses du vaccin. Tout a très bien marché. Après quelques balbutiements du serveur de l'Etat, je me suis inscrit pour la première vaccination et ai obtenu un rendez-vous le lendemain; un deuxième a suivi quatre semaines plus tard, les deux confirmés sur mon portable. Aucun effet secondaire! Après cela, j'ai pu revoir mes petits-enfants sans crainte. Quel privilège!

Je ne cache pas qu'au début j'ai eu des doutes: s'injecter de l'acide ribonucléique d'un virus? Le laisser pénétrer dans mes cellules pour produire ses protéines virales? Il fallait rapidement réaliser que c'est ce qui arrive chaque fois qu'un virus nous infecte ou quand nous sommes vaccinés par des virus atténués contre la rubéole, la rougeole ou les oreillons. Chaque fois, les virus nous forcent à produire de milliers de leurs molécules virales à ARNm... En plus, les nouveaux vaccins à ARNm sont beaucoup plus raffinés, car il n'y a pas le danger qu'un virus atténué se reconvertisse en un mutant virulent ou que l'ARN s'intègre à notre $\mathrm{ADN}$, comme c'est le cas avec des rétrovirus et leur retrotransférase. Les vaccins à ARNm font synthétiser juste la protéine significative de surface dont les anticorps nous protégeront contre l'attachement du virus. Et enfin, les résultats ont été spectaculaires et au-delà de toute espérance: 95\% d'efficacité!

Je ne comprends pas que des médecins refusent de se faire vacciner: pourquoi ne veulent-ils pas se protéger et protéger les autres?

Cependant, une fois vacciné, j'ai été envahi par d'autres doutes. Pourquoi moi? Moi avec ma retraite de l'Etat, ma maison, mon jardin et un ordinateur, avec lequel je peux regarder concerts et théâtres? Clairement, je fais partie des personnes privilégiées de cette épidémie. Pourquoi ne pas vacciner d'abord les plus jeunes qui ont encore toute la vie devant eux, pourquoi pas ceux qui sont beaucoup plus exposés au virus, comme par exemple la caissière des grandes surfaces? N'aurais-je pas dû leur laisser mes doses de vaccin? Et surtout aux médecins et aux soignants des EMS, des hôpitaux et des soins à domicile?

Parmi les soignants, il y a encore et toujours une grande partie qui ne veut pas se faire vacciner. A eux, je n'ai pas chipé de dose. Soit dit en passant, je ne comprends pas du tout que des médecins et des soignants refusent de se faire vacciner: comment, étant exposés jour après jour au virus, peuvent-ils ne pas vouloir se protéger et protéger les autres? Pourquoi ne consultent-

Cependant, une fois vacciné, j’ai été envahi par d'autres doutes. Pourquoi moi, qui fais partie des personnes privilégiées de cette épidémie?

ils pas des données scientifiques sérieuses et probantes attestant de l'efficacité et de l'innocuité du vaccin? Comment peut-on choisir une profession résolument altruiste et en même temps prendre le risque de transmettre une maladie potentiellement mortelle à des patients qui s'adressent à eux en toute confiance?

Evidemment, je suis rassuré que nos autorités aient décidé que les personnes à risque doivent être les premières à recevoir le vaccin. Et avec mes années, je suis à risque, comme témoignent quelques-uns de mes amis du même âge (quelques-uns même bien plus jeunes) fortement atteints par la maladie et ses séquelles, voire décédés. On dit que c'est pour ne pas engorger les soins intensifs des hôpitaux. Si on m'avait demandé, je leur aurais dit que de toute façon je ne voulais pas aller aux soins intensifs. J'avoue que ma motivation pour la vaccination contre le Covid-19 était plutôt (ou purement?) égoïste, semblable à celle de me faire vacciner chaque année contre la grippe: je veux simplement être protégé. J'ai donc avec un peu d'hypocrisie docilement suivi les directives de nos autorités sanitaires, ce qui m'a bien arrangé. Et maintenant j'espère qu'elles m'enverront bientôt mon passeport vaccinal afin que je puisse à nouveau voyager, aller au cinéma, au théâtre et assister à des concerts. Encore des doutes? 